\title{
Presupuestos teóricos para la regulación jurídica de las cooperativas de consumo en Cuba
}

\author{
Orestes Rodríguez Musa y Leticia Isabel Ferro Álvarez² \\ Universidad de Pinar del Río, Cuba
}

Recibido: 05-06-2017

Aceptado: 14-07-2017

Sumario: I. Introducción. II. Definición de la cooperativa de consumo. III. La teoría del acto cooperativo y su concreción en las cooperativas de consumo. IV. Limitaciones jurídicas actuales para las cooperativas de consumo en Cuba. V. Los presupuestos teórico-jurídicos para la satisfacción de necesidades de consumo a través de cooperativas en Cuba. VI. Conclusiones. Bibliografía.

Resumen: El proceso de actualización del modelo socioeconómico cubano ha implicado la expansión de las cooperativas. Sin embargo, la legislación que regula este proceso no concibe a las cooperativas de consumo, aun cuando las dificultades para el consumo de artículos vitales para las personas resultan evidentes. Por tanto, el objetivo de este trabajo es fundamentar los presupuestos teóricos en que debe sustentarse la regulación jurídica de las cooperativas en Cuba, a fin de que conciba a las cooperativas de consumo como un medio para la satisfacción de las necesidades de sus asociados y de la comunidad. Para ello se parte de una aproximación a la definición de las cooperativas de consumo. A continuación, se analizan las actuales limitaciones jurídicas para la instrumentación de este tipo de cooperativas en Cuba, y se termina argumentando los presupuestos teórico-jurídicos para este propósito.

Palabras clave: cooperativa; consumo.

1 Doctor en Ciencias Jurídicas por la Facultad de Derecho de la Universidad de la Habana (2016). Profesor del Departamento de Derecho de la Universidad de Pinar del Río, Cuba. Investigador del Centro de Estudios de Desarrollo Cooperativo y Comunitario (CEDECOM) con sede en la propia Universidad, así como de la Asociación Internacional de Derecho Cooperativo (AIDC), adscrita a la Universidad de Deusto, España. E-mail: musa@upr.edu.cu

2 Licenciada en Derecho por la Universidad de Pinar del Río, Cuba (2016). Graduada más integral de su curso en esta institución. Actualmente funge como asesora jurídica. 


\begin{abstract}
The updating process of the Cuban social and economic model has given rise to the expansion of cooperatives. However, the legislation regulating this process does not envisage consumer cooperatives, even if the difficulties regarding essential commodity consumption among people seem evident. Therefore, this paper aims to lay down the theoretical assumptions that should underpin the legal regulations of cooperatives in Cuba so that consumer cooperatives can be conceived as a means to meet the needs of their members and the community at large. To this end, an approach to the definition of consumer cooperatives is developed. Then, the current legal limitations for the implementation of this type of cooperatives in Cuba are analysed to finally discuss the theoretical and legal assumptions in this regard.
\end{abstract}

Keywords: Cooperative; consumption. 


\section{Introducción}

A nivel internacional las cooperativas surgen como parte del movimiento asociacionista devenido en Europa Occidental a finales del siglo XVIII. Producto a la necesidad de la clase obrera de agruparse para conseguir el suministro de alimentos, ropa y artículos de primera necesidad, es que se crea esta forma de empresa de administración democrática. Se constituyen así las cooperativas de consumo para brindar a la población trabajadora mejores condiciones de precio, calidad y formas de pago.

El año 1844 marcó un hito en la historia de las cooperativas como formas societarias. La experiencia de los Pioneros de Rochdale, primera cooperativa de consumo en Europa, sentó las bases y estatutos para el desenvolvimiento de estas entidades. De tal forma, se marcaba el punto de partida para el movimiento cooperativo moderno, así como para su posterior definición y alcance de los principios y valores que promulgaban.

Debido al desarrollo de nuevas tendencias y a la rápida implantación de avances tecnológicos, se hace insoslayable la constante evolución de los hábitos de consumo, una de las más básicas necesidades humanas. Esta situación expone a la población a condiciones donde imperan los altos precios, la adulteración de los artículos de consumo, la acción de intermediarios inescrupulosos, las inhumanas condiciones de trabajo y bajos salarios. Ante estas condiciones los Estados se han mostrado incompetentes, de ahí que se consoliden iniciativas de cooperación como lo son las cooperativas de consumo.

Al establecer una relación género-especie entre las cooperativas y las cooperativas de consumo respectivamente, estas últimas se destacan por presenciar características específicas que individualizan su campo de acción. Entre sus peculiaridad se encuentra la satisfacción de necesidades básicas de sus asociados, que a su vez son propietarios de la empresa que gestiona los productos que ellos consumen.

Actualmente son disímiles las cooperativas que gozan de gran prestigio como entidades reguladoras de precios, las cuales encuentran amparo legal para su regulación y funcionamiento en normativas propias de las cooperativas. Sin embargo, existen casos donde el marco legal aplicable a ellas, obvia su esencia, en tanto no las concibe como entidades destinadas a satisfacer las necesidades socioeconómicas de sus asociados, sino que las secuestra en figuras jurídicas de naturaleza diferente.

En Cuba, constan experiencias prácticas y legislativas sobre la institución que se estudia, que datan desde la colonia y se evidencian hasta 
los primeros años de la Revolución. Pero con la generalización de la intervención estatal en la economía, priorizan solo las de tipo agropecuario, destinadas a la producción agropecuaria y a la obtención de créditos y servicios estatales para los campesinos.

Sin embargo, tras los debates del VI Congreso del Partido se planteó el programa político para la regulación y funcionamiento de las cooperativas no agropecuarias (CNA), lo cual derivó en un marco legal con carácter experimental, destinado a regular esta forma de gestión no estatal en sectores diferentes al agropecuario.

La necesidad de encauzar y potenciar estas nuevas formas de gestión no estatal, se refuerza con el hecho de que en Cuba existen múltiples necesidades socioeconómicas que las empresas estatales y otros sujetos de más reciente aparición, no han sido capaces de satisfacer. De hecho, las necesidades de consumo de primer orden, especialmente la de alimento, es un tema prioritario para la Dirección del país, al punto de considerársele como un asunto de seguridad nacional (VENTURA, 2015). Sin embargo, el paquete legal destinado a la regulación de las CNA, publicado en la Gaceta Oficial No. 53 (extraordinaria), de 11 de diciembre de 2012, no propicia el aprovechamiento para la satisfacción de necesidades de consumo mediantes estas formas de gestión.

Tales limitaciones son resultado del proceso de cooperativización, el cual ha funcionado más como un instrumento gubernamental para «ir desprendiendo del Estado actividades productivas y de servicios que no le corresponden y lo desvían de la conducción de los procesos económicos, sociales y políticos principales», que como un medio para satisfacer las necesidades comunes de los trabajadores. De hecho, la anuencia para la aprobación de las CNA ha dependido más de las «prioridades» del país y de los territorios, definidas por el Gobierno mediante una «política» discrecional, que de la voluntad de los sujetos para asociarse. Esto explica -entre otros factores- el refrenamiento de la espontánea proliferación de las CNA en varias esferas de la economía, sobre todo cuando provienen de cuentapropistas que buscan colectivizar sus tareas como opción al trabajo aislado o en dependencia.

Es entonces, que la insatisfacción de las necesidades de consumo en Cuba, se presenta como una realidad latente que requiere concebir jurídicamente a las cooperativas de tal modo que puedan contribuir a la satisfacción de este tipo de necesidades de sus asociados. Sin embargo, y a pesar de la importancia que reviste el asunto, no se conocen investigaciones precedentes sobre las cooperativas de consumo en Cuba en la última mitad de siglo. 
Sobre esta base, el objetivo de este trabajo es fundamentar los presupuestos teóricos en que debe sustentarse la regulación jurídica de las cooperativas en Cuba, a fin de que conciba a las cooperativas de consumo como un medio para la satisfacción de las necesidades de sus asociados y de la comunidad.

Los métodos empleados fueron el histórico-jurídico; el jurídico-doctrinal y el análisis de documentos. En un primer momento se analiza, desde un punto de vista teórico, al vínculo cooperativo y al acto cooperativo. A continuación se valoran las limitaciones jurídico-prácticas para concebir a la cooperativa de consumo como un medio para la satisfacción de las necesidades de sus asociados y de la comunidad. Por último, y antes de arribar a conclusiones, se argumentan los presupuestos teóricos para superar estas limitaciones.

\section{Definición de la cooperativa de consumo}

Las cooperativas, acompañadas de valores y principios propios*, tienen como finalidad satisfacer las diversas necesidades de sus asociados, las cuales resultan tan disímiles como los tipos cooperativos.

Si bien existen principios y valores generales aplicables a todas las cooperativas*, otras normas especiales, reglas técnicas y disposiciones, son atinentes a determinados tipos. Una correcta clasificación de estas entidades puede ayudar a una interpretación/aplicación adecuada de tales disposiciones.

En tal sentido resalta la clasificación dada por KaPLAN DE DRIMER y DRIMER $(1981,153-161)$ de acuerdo a la naturaleza de las funciones que desempeñan estas entidades con respecto a sus asociados, donde se distinguen tres tipos fundamentales de cooperativas: las de colocación de la producción; las de trabajo y las de distribución.

Centrándonos en nuestro objeto de estudio, debemos decir que la función reconocida a las cooperativas de distribución, es la de proporcionar a sus asociados los artículos y servicios que estos necesitan, en las mejores condiciones posibles de calidad y precio. Para ello, estas cooperativas compran al por mayor o producen en fábricas propias los artículos correspondientes y realizan por sí mismas o contratan con terceros los servicios requeridos, que son luego respectivamente, adquiridos o utilizados por sus asociados.

Las diferencias entre el costo que tienen esos artículos o servicios para las cooperativas de distribución (precio de compra o de producción, sueldos, gastos, alquileres, gastos generales, etc.) y los precios que ellas perciben por el suministro de tales artículos o servicios a los 
asociados, constituyen los excedentes de este tipo de cooperativas; y una vez provistos determinados fondos o reservas, retornan o se devuelven a los asociados en proporción al monto de sus respectivas operaciones, o bien se destinan a diversas finalidades comunes.

El presente tipo de cooperativas de distribución abarca dos principales subtipos, las de provisión, que suministran a sus asociados (agricultores, pescadores, artesanos, profesionales, pequeños y medianos industriales o comerciantes, etc.) los artículos y servicios que necesitan para desempeñar su correspondiente actividad económica (maquinaria, materias primas, mercaderías, semillas, forrajes, repuestos, servicios de transporte de carga, etc.); y las de consumo, que proporcionan a sus asociados artículos y servicios de uso personal y familiar (alimentos, ropas, artículos de farmacia y perfumería, artefactos eléctricos, muebles, utilización de cámaras frigoríficas para guardar alimentos, uso de medios de transporte, etc.).

FAURA y UDINA (2004) las definen como "sociedades que gestionan la distribución de productos o servicios, de cualquier clase, para los consumidores finales», asociando a las cooperativas con las sociedades y desconociendo además que los consumidores finales, a los que hace alusión, son a su vez, sus propietarios.

Para SANCHIS y ReVuelto $(1995,143)$ constituyen «entidades sin fines de lucro en las cuales los excedentes se devuelven en forma de retornos cooperativos a los socios en función de las compras efectuadas por los mismos». En esta concepción no se alude claramente al objeto propio de este tipo de cooperativas, aunque se reconoce que evidencia algunas características importantes como lo son la ausencia de ánimo de lucro, que se concreta -entre otras formas - en la devolución de los excedentes en forma de retorno.

Volviendo a KAPLAN DE DRIMER y DRIMER $(1981,144)$, estos las identifican como «...cooperativas que se ocupan de distribuir a sus asociados artículos y servicios de uso personal y del hogar, en condiciones satisfactorias en cuanto a precio, calidad, medida, oportunidad, etc. Procurando perfeccionar los procesos económicos correspondientes y evitar la acción de la intermediación superflua, de los acuerdos monopolistas y de otros factores que distorsionan esos procesos y perjudican a las personas en su carácter general de consumidores».

Esta definición acierta en tanto no les entiende como sociedades, sino como cooperativas, de donde se entiende que su esencia difiere de las entidades mercantiles, además de que precisa que los destinatarios principales de su actividad de servicio son sus propios asociados.

Es por eso que este tipo de cooperativas han sido identificadas por la $\mathrm{ACl}$ (2004) como reguladoras de precios, pues la competencia que 
rodea a estas entidades se ve obligada a ajustar los valores de sus productos para mantenerse en el mercado; además de que informan y forman a las personas en un ambiente de consumo responsable. También es de destacar que en su evolución, las cooperativas de consumo han incorporado a los trabajadores como socios de trabajo, por lo que también contribuyen a generar empleo (ToRIBIOS, 2014).

Es común que estas entidades extiendan sus servicios a terceros no socios. En tales casos suele la cooperativa, en la medida en que el régimen jurídico al que se someta lo condicione, contribuir directamente al desarrollo de la comunidad en que se enmarca.

Por tanto, la cooperativa de consumo, a la vez que cumplen con los principios y valores comunes a todas las cooperativas, poseen características propias que hacen sobresalir la múltiple condición del consumidor/propietario/usuario, resultando los propios miembros los beneficiarios finales de los productos o servicios de consumo que la cooperativa se ocupa de distribuir.

\section{La teoría del acto cooperativo y su concreción en las cooperativas de consumo}

PASTORINo advierte que "...la compra que hace el cliente en el almacén de la sociedad ordinaria determina un negocio jurídico distinto del que hace el asociado cuando se avitualla en su cooperativa de consumo...» (citado por García MülLER, 2012). Esta cita destaca la diferencia central entre el modo de operar de una entidad no cooperativa respecto a una cooperativa, la cual reside en que en el primer caso, siempre lo hacen como terceros; pero cuando cualquier cooperador aparece vinculándose con su cooperativa, no es un tercero, ni puede serlo, sino que «integra la cooperativa en la que ha puesto capital y cuya asamblea compone, y que ha contribuido a formar con el preciso propósito de operar en ella» (REzZÓnICO, 2006, 388).

Teniendo en cuenta esta unidad, es necesario un negocio jurídico que contenga el actuar del asociado en su cooperativa. Por ello, se hace necesario la configuración jurídica de la terminología, conceptos, categorías, rasgos, estructuras y procedimientos propios de la cooperativa como institución sui géneris que tiene como razón de ser la satisfacción de las necesidades de sus socios, lo cual no niega su implicación dentro de los principios y normas supra-ordenadoras de cada país, que le impondrán límites y responsabilidades a esta figura.

En la actualidad, la mayoría de los países contienen normativas propias para las cooperativas, pero no en todos los casos el legislador, in- 
térprete y/o aplicador de la norma jurídica consigue visualizar la naturaleza especial de la institución, máxime cuando entorno a ella existe un debate profundo (Rodríguez MusA, 2017, 98-104). En tal sentido suele confundirse la entidad cooperativa con otras figuras y la tipificación legal de sus rasgos se fuerza en leyes que no responden completamente a su esencia.

A criterio del autor, sería ingenuo no percatarse de que estas posturas son expresión de la dinámica absorbente del capital. A fin de cuentas, el Derecho posee un carácter instrumental al servicio de los intereses económico-políticos prevalecientes en cada contexto. No obstante, la naturaleza de las instituciones jurídicas la determinan sus rasgos intrínsecos, cuyas cualidades sociales, en el caso de la cooperativa, desborda los contornos societario-mercantiles.

En tal sentido resalta la vertiente doctrinal que considera a la cooperativa como una categoría autónoma. En ella no se acepta el carácter societario de la cooperativa, por cuanto carece de ánimo de lucro, requisito imprescindible para considerársele como tal. A su vez, se niega que sean asociaciones propiamente dichas, pues estas no alcanzan a englobar su contenido empresarial y además, por tener una serie de rasgos diferenciadores que delimitan su identidad. Por tanto, el principal mérito de esta postura es ser leal a la identidad cooperativa, conciliando, en una misma fórmula jurídica, su dimensión económica y su alto contenido social.

Destaca en su defensa VICENT ChULIÁ (1991, 1019-1021), para quién esta es una institución sui generis, que se diferencia de la sociedad, entre otros aspectos, en la estructura del patrimonio, puesto que si en esta es todo repartible, en la cooperativa existe una parte irrepartible. También se diferencian en los derechos de sus miembros, que en la cooperativa solo pueden exigir la liquidación de sus aportaciones, cuando en la sociedad podría liquidarse todo el capital social; unido a que tienen derechos políticos equivalentes a los del socio, pero ejercidos con absoluta igualdad. Además soportan deberes de asistir y votar en Asamblea, aceptar y ejercer los cargos (salvo justa causa de excusa) y de utilizar los servicios de la cooperativa.

Sin minimizar la importancia de los aspectos antes señalados, el hecho de que la cooperativa se presente como una nueva categoría descansa - a criterio de los autores - fundamentalmente en su finalidad. Esto decide lo esencial: la misión que le corresponde en el sistema socioeconómico en que se desenvuelve.

Para explicar lo anterior se ha estructurado la teoría del «acto cooperativo», de factura latinoamericana y que tiene entre sus principales exponentes a Salinas Puente en México, Bulgarell en Brasil y 
a Cracogna en Argentina, además de que se ha concretado en la Ley Marco para las Cooperativas de América Latina (ACl, 2009, artículo 7) y en la legislación de al menos 14 países de la región (GARCía MülleR, 2015, 19-31; TORRES MORALES) ${ }^{3}$.

Este acto constituye el medio o instrumento principal para la realización práctica de la razón de ser de la cooperativa. SALINAS PUENTE $(1954,22)$ se refiere a él como "el supuesto jurídico, ausente de lucro y de intermediación, que realiza la cooperativa en cumplimiento de un fin preponderantemente económico y de utilidad social».

En la misma dirección explica Cracogna $(1986,21)$ las notas esenciales y consustanciales a estos actos que permiten afirmar que no tienen una naturaleza civil ni comercial ni otra cualquiera, sino una que les es propia y que los distingue dada la propia finalidad de la institución: a) intervención de socio y cooperativa; b) objeto del acto idéntico al objeto de la cooperativa; y c) espíritu de servicio, donde hay un corpus (el objeto material o inmaterial sobre el que versa) y un animus (el espíritu de servicio que informa la relación). Por consiguiente, en la cooperativa «...el fin no es el lucro, sino el servicio al socio; no es la ganancia, sino la satisfacción de sus necesidades, pues, esas necesidades son las que unieron a los socios para formar la cooperativa y mediante el aporte y esfuerzo mutuo, auto-proveerse de su fuente de trabajo, de servicios, de abastecimiento o comercialización de sus productos, según el tipo de cooperativa» (Naranjo Mena, 2014). Por ejemplo, en una cooperativa de trabajo, la actividad económica que se desarrolla ( $V$. gr.: gastronomía, trasporte, gestoría de alojamiento, etc.) es solo un medio que sirve al propósito superior de satisfacer la necesidad de un empleo digno y óptimamente retribuido a sus asociados (CRACOGNA, 1992, 171).

Esta perspectiva de servicio al socio también se observa en las cooperativas de consumo, donde "la cooperativa no produce una renta propia porque cuando realiza su actividad cobra el servicio a un precio que se estima conforme con el mercado. Pero ese precio es provisional... la cooperativa le cobra demás al asociado cuando retira artículos de consumo, para cubrir sus gastos... porque no sabe exactamente cuáles son sus costos. Cobra pues un precio aproximado al del mercado, y al final del ejercicio, se efectúan el balance y estado de resultados, entonces aparece la verdadera y definitiva determinación del precio del servicio. Allí se determina si lo que se le cobró al asociado en la

3 V. gr.: Brasil: (Ley No. 5764 del 16.12.71); Argentina: (Ley 20337 del 15.05.73); Uruguay: (Ley 15645 del 9.10.84); Honduras: (Decreto No. 65-87 del 20.05.87); Colombia: (Ley 79 del 23.12.88); México: (Ley del 03.08.94); Paraguay: (Ley 438 del 21.10.94). 
cooperativa de consumo es demás respecto del precio que debió habérsele cobrado. Entonces se hace un ajuste que resulta de la distribución del excedente por vía del retorno. En consecuencia, en la cooperativa no quedan ganancia, no quedan rentas, no quedan beneficios porque lo que se cobró demás se devuelve al asociado por vía de la prorrata del retorno (CRACOGNA, 1992, 171).

La actividad empresarial no es un fin en sí mismo, sino un medio para la consecución de determinado objetivo social. El capital sirve al hombre y no a la inversa.

Si la cooperativa surge y se organiza en atención a otros propósitos diferentes a los de servir a sus asociados, entonces estaremos ante una falsa cooperativa, cuyo fin quizás no sea ilegítimo en sí mismo, pero sí por la forma jurídica que asume. Esta desnaturalización, que por lo general aparta a la institución de su carácter social, puede llegar hasta la concepción jurídica de la figura, que muchas veces la entiende y la proyecta no hacia dentro, sino hacia afuera, buscando insertarla en la lógica del mercado, en lugar de oponerla a ella.

Por tanto, es el acto cooperativo la piedra angular para sostener la naturaleza peculiar de las relaciones sociales que resultan al interior de lo que llama Bulgarell $(1967,107)$ el "círculo cerrado» ${ }^{4}$ de estas formas asociativas, es decir, entre ella y sus asociados, y también en el ámbito cooperativo, o sea, entre entidades de este tipo que colaboran unas con las otras en cumplimiento de su objetivo social ( $\mathrm{ACl}, 2009$, artículo 7).

Sin embargo, lo anterior no desconoce que, de forma creciente, las cooperativas pueden prestar servicios propios de su objeto social a no socios, en cuyo caso estas relaciones se regirán no ya por la norma estatutaria y las normas cooperativas especiales, sino por el Derecho común ( $V$ gr.: laboral, mercantil o civil, según sea el caso). A criterio de los autores, en estos supuestos, so pena de desnaturalizarse la figura, también los actos jurídicos que realice deben contener animus social. La naturaleza especial de estos actos sería solo salvable si los beneficios que generan se revierten hacia los no socios sujetos de tales, por ejemplo, a través de la creación de un fondo especial para este propósito (ACl, 2009, artículo 8).

4 Distinguió la existencia de dos tipos de relaciones en las cooperativas: una derivada de los actos que la cooperativa practica con sus asociados en cumplimiento de su objeto social, y otra derivada de los actos que realiza con terceros no socios. A los primeros, que se realizan de manera interna, en un «círculo cerrado» los llamó actos cooperativos. 
En tal sentido se advierte sobre el peligro de que algunas cooperativas, consciente e inconscientemente, han abandonado sus normas fundamentales de organización y funcionamiento, corriendo dos grandes riesgos: el de desnaturalización y el de desmutualización. El primero de ellos estriba en que se acepten disposiciones que contradicen las claras normas de organización y funcionamiento de origen rochdaliano ya adaptadas y perfeccionadas por la $\mathrm{ACl}$. Y el segundo se refiere a la posibilidad de que una sociedad cooperativa sea trasformada en una sociedad anónima, o de otro tipo, que implique su privatización (KAPLAN DE DRIMER, 2001, 167).

Se puede arribar entonces a la conclusión de que el acto cooperativo es un reflejo fiel y consecuente de la identidad cooperativa, o sea, su razón de ser, la manera más adecuada de que el derecho capte y tipifique la esencia de las cooperativas. Es una construcción teórico-jurídica que responde a la finalidad de estas entidades y la forma más apropiada de regular jurídicamente la relación no lucrativa de la cooperativa con sus asociados y de que el derecho proteja y distinga en su tratamiento esas especiales relaciones con respecto a las que realizan otras entidades con otra naturaleza.

\section{Limitaciones jurídicas actuales para las cooperativas de consumo en Cuba}

Desde el VI Congreso del Partido Comunista de Cuba (2011), celebrado en abril de 2011, con la aprobación de los Lineamientos de la Política Económica y Social del Partido y la Revolución, se sentaron las pautas necesarias para conducir el proceso de actualización del modelo económico socialista en que hoy se encuentra inmerso el país. Los puntos del 25 al 29 de estos Lineamientos, agrupados bajo el título de "LAS COOPERATIVAS», establecen los aspectos básicos para la inserción de éstas en un nuevo «MODELO DE GESTIÓN ECONÓMICA» que planea expandir a estas formas asociativas hacia otras esferas de la economía diferentes a la agropecuaria ${ }^{5}$.

Los puntos de los Lineamientos que refieren a las cooperativas han sido desarrollados por un paquete legislativo, con carácter experimental. Estas disposiciones, entraron en vigor el 11 de diciembre de 2012 cuando se publicó la Gaceta Oficial Extraordinaria No. 53, contentiva

5 Estos Lineamientos fueron revisados por el VII CONGRESO dEL PARTIDO COMUNISTA DE CUBA (2016), y el nuevo documento ratifica y actualiza esta política. 
de dos Decretos-Leyes, el No. 305, de 15 de noviembre de 2012, «De las Cooperativas No Agropecuarias» y el No. 306, de 17 de noviembre del mismo año, «Del Régimen Especial de Seguridad Social de los Socios de las Cooperativas No Agropecuarias»; un Decreto, el No. 309, del 28 de noviembre de 2012, "Reglamento de las Cooperativas no Agropecuarias»; entre otras disposiciones normativas que configuran el marco regulatorio provisional para estas nuevas cooperativas en Cuba6.

Teniendo en cuenta las novedades acontecidas, se identifican como limitaciones jurídicas actuales de la institución cooperativa en Cuba, que responde a insuficiencias arrastradas de etapas precedentes y a otras más recientes, las siguientes:

1. Persisten las insuficiencias en su regulación constitucional, en tanto el magno texto no tutela el derecho de otros trabajadores diferentes a los agricultores pequeños a asociarse en cooperativas y, por tanto, no reconoce su existencia más allá del sector agropecuario de la economía. Además, reduce su naturaleza jurídica a forma de propiedad, descuidando así el vínculo cooperativo, la finalidad de servicio que le asiste, y los valores y principios que le resultan consustanciales. En definitiva, no contiene una institucionalización de la cooperativa como figura autónoma, en relación de complementariedad con otros entes públicos y privados, para la satisfacción de las necesidades socioeconómicas de las personas.

2. Ausencia de una concepción armonizadora y homogénea acerca de las cooperativas y su naturaleza jurídica, lo cual está directamente ligado a la no existencia de una legislación general unificadora y armonizadora del sector, que se expresa actualmente en la pluralidad de normas, dispersas (algunas con carácter experimental), que lo fracturan entre lo agropecuario y lo no agropecuario, y que presentan poca sistematicidad y coherencia entre sí. Esto unido a antinomias o contradicciones derivadas del reglamentarismo excesivo y de la diversidad en las bases contextuales a las que responden. De esta forma quedan en entredicho los rasgos y principios de la institución, así como

${ }^{6}$ Este paquete legal inicial, ha sido actualizado o complementado hasta la fecha con otras disposiciones que implementan medidas emergentes para corregir algunas de las insuficiencias que se han ido presentando durante la marcha del experimento; pero que complejizan aún más la plataforma legal de las cooperativas en el país. En este sentido lo más significativo la Gaceta Oficial No. 12 Extraordinaria de 13 de abril de 2016, con un amplio conjunto de disposiciones administrativas de los Ministerios de Comercio Interior, Finanzas y Precios y Seguridad Social. 
la posibilidad de determinar normas supletorias aplicables sin distorsionarle su naturaleza. Todo ello redunda en afectaciones a la identidad de las cooperativas y al empoderamiento del que precisan para transformar su medio económico-social.

3. Permanencia de un modelo absorbente en las relaciones de la cooperativa con el Estado, que aunque en los últimos años muestra una tendencia a su flexibilización (Rodríguez MuSA, $2013,142)$, afecta la autonomía de esta desde el proceso para su constitución y hasta el de su disolución, pasando por la determinación de su objeto social, por la planificación de su actividad económica y por las características de sus relaciones contractuales. A esto se une la ampliación de los entes públicos que interactúan con las cooperativas promoviéndolas, autorizándolas, calificándolas y controlándolas, los cuales se han diversificado tanto como las esferas de la economía en que estas funcionan y, con ellos, los métodos, políticas y disposiciones que se le aplican. Tal atomización también limita la consolidación de la identidad de la figura por sobre la esfera de la economía en que se desarrolle.

En la agudización de los efectos negativos de estas limitaciones ha incidido la generalizada falta de cultura jurídico-cooperativa, que ha derivado en que el legislador, el aplicador de la norma cooperativa y la sociedad en general, arrastren hacia estas formas asociativas los esquemas de la empresa estatal o los importen de las formas capitalistas. Pese a ello, se ha autorizado la creación de 514 CNA, de las cuales solo 383 están funcionando, 9 se han retirado del experimento y 122 están pendientes de su constitución, cifras que por sí solas dejan entrever lo difícil del proceso de constitución. Aproximadamente el 88\% se concentra en tres sectores: Comercio, Gastronomía, y Servicios Técnicos y Personales (59\%); Construcción (19\%); e Industria (10\%) (TRISTÁ ARBEZÚ, 2015 y ONEI, 2016). Pero ninguna de ellas es una cooperativa de consumo.

De forma general, las principales limitaciones de la regulación jurídica para configurar cooperativas de consumo en Cuba son las siguientes:

1. En el ordenamiento jurídico cubano la CNA se concibe como una empresa mercantil. Por tanto su regulación jurídica no se encamina prioritariamente a ordenar el servicio de esta a sus asociados.

2. Se asume una visión reduccionista de los objetivos de las cooperativas, limitándolas a la producción y los servicios, definidos no en función de las necesidades socioeconómica de sus asociados, sino de la actividad económica que realizan. 
3. Se utiliza la contratación económica con el Estado y el cobro de impuestos sobre actos con terceros, como mecanismos indirectos de distribución social de los beneficios que las cooperativas generan, y no la actitud de autoservicio de la cooperativa a sus asociados.

4. En consecuencia al no sustentarse la regulación jurídica de las CNA en Cuba en la teoría del acto cooperativo y en el vínculo cooperativo tampoco concibe las cooperativas de consumo como un medio de satisfacción de las necesidades socioeconómicas de las personas.

Tanto los Lineamientos del Partido como el DL305/12 y su reglamento muestran insuficiencias en torno a las concepciones teóricas de las cooperativas. En especial se evidencia un reduccionismo legislativo que afecta la adecuada previsión normativa de las cooperativas de consumo. Por ende, se requiere de una fundamentación teórica del vínculo y del acto cooperativo como presupuestos para la concepción de las cooperativas de consumo como un medio para la satisfacción de las necesidades de alimentos de sus asociados y de la comunidad.

\section{Los presupuestos teórico-jurídicos para la satisfacción de necesidades de consumo a través de cooperativas en Cuba}

En Cuba, las causas de la insatisfacción de las necesidades de consumo no solo están enfocadas en las dificultades durante el proceso productivo, también son motivo de análisis los mecanismos de distribución.

El problema muchas veces reside en que los productos transitan de una mano a otra beneficiando a los intermediarios inescrupulosos que, amparados en la oferta y demanda, abusan de la población sobregirando los precios de los artículos, incluso, de primera necesidad. Por su parte el Estado, tampoco ha conseguido complacer esta demanda, ni mediante sus insuficientes mecanismos de subsidios, ni mediante los mercados estatales que sufren de las deficiencias de la distribución y de la competencia (muchas veces informal) de los otros sujetos económicos.

Tampoco se ha encauzado legalmente a las cooperativas para que se opongan a la lógica especulativa del mercado, en función de la satisfacción de necesidades socioeconómicas de la población. Más bien se les ha utilizado como un medio para generar nuevas fuentes de empleo, cuando el Estado se ha desprendido de los objetivos económicos de menor trascendencia para el país. 
Por tanto, no se ha concebido legalmente la verdadera esencia de las cooperativas, la cual radica en la finalidad de servicio de sus actos con y para sus asociados, y que irradian hacia la comunidad. Se obvian así, los caracteres básicos del vínculo cooperativo, que deben encaminar a la cooperativa a reconocer en sus asociados a los principales destinatarios de su actividad socioeconómica.

Sobre esta base, cabe precisar que para la conformación de una ley encaminada a regular las cooperativas de manera integral y conforme a su naturaleza, de tal forma que también resguarden a las personas que pretendan asociarse en cooperativas para satisfacer mediante la gestión de esta empresa sus necesidades de consumo, se requiere observar los siguientes presupuestos:

a) La finalidad de las cooperativas es, en primera instancia, la satisfacción de las necesidades de sus asociados

En este sentido, la normativa cubana que regula con carácter experimental a las CNA, debiera aludir, como finalidad de estas formas asociativas, la satisfacción de las necesidades socioeconómicas de sus miembros, en tanto la cooperativa surge para y por sus asociados. El satisfacer en primer orden los requerimientos estatales, es un mecanismo indirecto de distribución social de la riqueza que puede sustituirse por más cooperativas de consumo articuladas en función de la satisfacción de las necesidades de sus asociados como la vía para eliminar la especulación y el lucro del mercado. De esta forma el accionar de estas tributaría directamente a la sociedad.

La cooperativa entonces, no puede ser entendida como un mecanismo para descongestionar al Estado de aquellas funciones que no le corresponden y lo desvían de la condición de los procesos económicos, sociales y políticos. Y aunque ciertamente es una fuente de empleo; su esencia es satisfacer las necesidades de sus miembros, los cuales, mediante esta forma de gestión democrática, pretenden satisfacer sus necesidades comunes, las que pueden ser de diversa índole.

La ley cooperativa, por ende, no tiene que ser exhaustiva a la hora de especificar las necesidades que las cooperativas pretenden satisfacer, y mucho menos encuadrar sus objetos a sectores determinados de la economía. Esta cuestión debe partir de la autonomía de estas entidades, y encontrar amparo en sus Estatutos. Los objetivos socioeconómicos pueden ser tan amplios como sean las necesidades de sus asociados.

En otro sentido, la ley tiene que encaminarse a que las cooperativas tengan como primera finalidad, la de satisfacer las necesidades de sus 
miembros y no la obtención de un lucro. De tal manera, el acto cooperativo reaparece según la definición de BASÁÑEZ (citado por CORBELLA, 1990, 63) como: «...un acto interno entre el asociado y su cooperativa, por el cual la segunda presta al primero un servicio (...), en cumplimiento de su objeto social». Para ello, un reto a superar por parte del legislador cubano, reside en concebir a la cooperativa en base a satisfacer las necesidades de sus miembros. Esta es una forma de reconocer que los actos que realizan son actos propiamente cooperativos, puesto a que son los que efectúan las cooperativas con sus socios.

\section{b) El reconocimiento de los roles de socio-usuario en los sujetos que se asocian}

Estas relaciones se dan debido a que las cooperativas deben ser organizaciones de participación, ya que sus socios son, simultáneamente, capitalistas* y usuarios de la actividad empresarial, como define CoQue (2008). Por tanto, tienen doble interés en que sus empresas funcionen según los objetivos que motivaron la asociación económica.

En tal sentido, debe reconocerse la esencia participativa que tiene la figura cooperativa, debido a los vínculos especialmente fuertes que crea con sus socios. Ello consiste en la superposición consciente en las mismas personas de dos papeles (propietario del capital y usuario), lo que generaría el concepto integral de socio.

Si se tuviese en cuenta la dualidad de funciones en la cooperativa, se duplicarían las relaciones entre la entidad y sus socios. En correspondencia con ello, la rentabilidad del capital puesto en juego, sería más un medio para alcanzar otros fines que un fin en sí mismo. Como efecto de este doble vínculo, los socios tendrían mayor interés por gobernar la entidad. Esto diferencia a las cooperativas de las sociedades de capital.

\section{c) Exención fiscal para los actos jurídicos cooperativos}

En el caso de las cooperativas el tratamiento tributario que se les aplique, debe asentarse en el reconocimiento de las diferencias que existen entre las sociedades mercantiles y las sociedades cooperativas, para darle a cada quien el tratamiento que le corresponde y que obedece a la naturaleza jurídica de estas organizaciones y al tipo de actos que ellas realizan.

El régimen tributario de las CNA es especial, más beneficioso que el general y, en ocasiones, que el de los trabajadores por cuenta propia: pa- 
gan un 5\% menos en la contribución a la seguridad social, es decir, un $20 \%$ en lugar del $25 \%$ que pagan los trabajadores por cuenta propia; en la escala del impuesto sobre utilidades que va del 10 al $45 \%$ en lugar del 15 y hasta el $50 \%$ para los trabajadores por cuenta propia; también ellas podrán deducir del impuesto sobre las utilidades del 100\% de los gastos (justificando solo el 60\%); y una exención per cápita igual al salario medio de la provincia multiplicado por el número de miembros de la cooperativa (Ley 113 de 2012, "Del Sistema Tributario»).

Lo anterior evidencia la voluntad política de favorecer la cooperativa como forma de gestión colectiva y democrática que - como regla - no implica el aprovechamiento de la fuerza de trabajo asalariada, lo cual llegará a ser fomento fiscal cuando efectivamente se flexibilice el proceso para formalizar la asociación.

Esto es apropiado porque son cooperativas de trabajo, donde la necesidad que se cubre es la de empleo y donde la actividad de producción o servicio de la cooperativa va dirigida a terceros a través de actos de comercio, y se cumple en tanto con la voluntad estatal de fortalecer esta figura como una forma de gestión no estatal viable para continuar con el perfeccionamiento del nuevo modelo económico; sin embargo, la implementación de las cooperativas de consumo en base a esta lógica sería insuficiente, en tanto en dicho tratamiento tributario especial aún no se visualiza lo esencial: que se asiente en la exención de los actos cooperativos.

Las cooperativas requieren de un tratamiento específico, que no violente su naturaleza jurídica, lo cual no debe confundirse con un mero régimen de privilegios. Una política más científica no exonera a las cooperativas de algunos tributos (estableciendo así beneficios o privilegios), sino que las declara no comprendidas en el ámbito del respectivo tributo.

No basta entonces, con entender las diferencias que entre una y otra actividad existen, sino que estas deben ser reconocidas a la hora de plantear las obligaciones fiscales a cumplir por cada una. Los actos cooperativos deben estar exentos de las obligaciones fiscales, toda vez que los actos que realizan las cooperativas con sus asociados no son lucrativos.

\section{d) La responsabilidad social cooperativa por los actos jurídicos con terceros debe ser directa}

En cuanto a la responsabilidad que derivan los actos de la cooperativa con terceros, que en el caso de las cooperativas de consumo, en principio podrían tacharse como actos de comercio lucrativos, vale un 
acercamiento o lo que se conoce como Responsabilidad Social Directa, diferente a la que las empresas realizan a través de la intermediación del Estado (indirecta), y que presupone "el compromiso consciente de sus directivos y trabajadores con la satisfacción de las necesidades y expectativas de su recurso humano y la comunidad en que se inserta, a partir de una gestión propia y de sus recursos, mediante el vínculo estable y sistemático con las organizaciones políticas, de masas y sociales de su ámbito interno y de su entorno inmediato» (Alfonso Alemán, 2008, 48).

La Responsabilidad Social Directa es consustancial a la cooperativa, para cuya materialización requiere del compromiso consciente; la participación real; una formación ética e ideológica basada en los valores que la identifican; así como utilidades que sustenten financieramente los diferentes proyectos sociales que desarrolla la entidad; y el reconocimiento y apoyo estatal a la acción social directa que deberá manifestarse, entre otros factores, en la adopción de instrumentos legales (ALFONSO ALEMÁN, 2008, 106-108).

Teniendo en cuenta que en Cuba no se incluyen disposiciones jurídicas que impongan la obligación de planificar, controlar, registrar, medir, evaluar e informar acerca del grado de cumplimiento de este tipo de responsabilidad social en las empresas cooperativas, el Centro de Estudios de Desarrollo Cooperativo y Comunitario, adscrito a la Universidad de Pinar del Río, ha propuesto un «Modelo de Gestión de la Responsabilidad Social Cooperativa Directa» en cuyos componentes principales se encuentran: a) el "Mercado Social Objetivo», referido al conjunto de necesidades y expectativas presentes en los ámbitos de actuación (interno y externo); b) el «Sistema de Indicadores Sociales» diseñados a partir de la operacionalización de los principios cooperativos y concretándose en aspectos para medir la gestión de la responsabilidad social interna7 y externa ${ }^{8}$; y c) el "Balance Social Cooperativo» que es una herramienta de información metódica que permite evaluar estáticamente el nivel de cumplimiento de las actividades que desarrolla la cooperativa para el cumplimiento de su misión social, en un período dado y que debe ser auditable?

7 V. gr.: Características socio demográficas del personal asociado; Relaciones laborales; Condiciones de trabajo; Ingresos de los asociados y distribución de utilidades; Ingreso Real Interno de los asociados; y Demandas y aspiraciones laborales.

8 V. gr.: Características socio demográficas de la comunidad; Relaciones sociales comunitarias; Condiciones sociales de la comunidad; Fondo Social Comunitario; Demandas y aspiraciones sociales de la comunidad; y Cooperación entre cooperativas.

9 También se define el Balance Social Cooperativo como «una herramienta de la gestión socioeconómica que facilita a las cooperativas medirse y rendir cuentas, a los/ as asociados/as — sus dueños/as - especialmente, y a todos los demás grupos de inte- 
El modelo que se comenta, evidencia que estas empresas no solo pueden realizar una intervención social directa que contribuye a la satisfacción de las necesidades sociales de su comunidad, sino que además esta intervención es factible de regulación jurídica, control y evaluación desde el aparato de poder y por las propias cooperativas.

A criterio de los autores, la materialización de esta responsabilidad social directa podría ser más efectiva cuando se diseñe la institución para realizar actos cooperativos de interés general, es decir, cuando se fundan en los mismos sujetos los asociados de la cooperativa con los destinatarios de un servicio "público», en tanto «...lo público puede constituir alternativamente un ámbito de autogestión de la sociedad civil... contrarrestando la tendencia vigente a la máxima mercantilización de las relaciones humanas [o su estatalización]. Al asumir la sociedad civil la autogestión a través de cooperativizarse servicios del ámbito de lo público, tiende a conformarse una economía... que potencia el control social, transparenta el escenario y las actuaciones, y desburocratiza la gestión...». Esto es lo que algunos autores llaman «lo público no estatal», más loable cuando se diseña y se practica desde lo local (ZILOCCHI, 2016, 20).

Por tanto, en la misma medida en que se consolide el escenario de coincidencia entre interés popular e interés cooperativo, así como de práctica consciente de responsabilidad social directa, carecería de sentido la intermediación del Estado para preservar el interés general a través de fórmulas como la autorización sobre el objeto social, los precios topados, el encargo estatal y el cobro de impuestos por actos lucrativos, lo cual constituye el ideal a alcanzar.

\section{Conclusiones}

1. El vínculo cooperativo, entendido como la superposición consciente en la misma persona de los roles de propietario del capital y usuario de la empresa, explica que los actos jurídicos más importantes que realiza la cooperativa sean aquellos que practican con sus miembros para satisfacer las necesidades socioeconómicas que determinaron la asociación.

\footnotetext{
rés que son impactados por su accionar en relación con el cumplimiento de su esencia o identidad, es decir, desde los valores y los principios cooperativos. Además de permitir el análisis interno de cada cooperativa, este caudal de información ayuda a construir la imagen del movimiento cooperativo sobre parámetros objetivos y fiables» (ACl-AMÉRICAS, 2016).
} 
2. Para que la cooperativa pueda fungir como un instrumento destinado a la satisfacción de las necesidades de consumo de sus asociados, eliminando la intermediación especulativa y el lucro, es pertinente que la regulación jurídica de la figura descanse tanto en el vínculo cooperativo, como en la teoría del acto jurídico cooperativo.

3. La regulación jurídica de las nuevas cooperativas no agropecuarias en Cuba, presenta limitaciones en su concepción que han reducido su manifestación a cooperativas de trabajo y las ha acercado a las sociedades lucrativas. Esto implica que el legislador tenga que acudir a los vínculos económicos y tributarios de la sociedad cooperativa con el Estado, para intentar garantizar la distribución social de la riqueza.

4. Para que la regulación jurídica de la cooperativa en Cuba, conciba las cooperativas de consumo como un medio para satisfacer las necesidades de este tipo de sus asociados y de la comunidad, es preciso que se asiente en la concepción de que la finalidad de las cooperativas es, en primera instancia, la satisfacción de las necesidades de sus asociados; en el reconocimiento de los roles de socio-usuario en los sujetos que se asocian; y en la exención fiscal para los actos jurídicos no lucrativos que la cooperativa realiza con sus asociados. Lo anterior no impide que la cooperativa de consumo establezca vínculos económicos con terceros, caso en los que el régimen jurídico de estos habrá de garantizar su contribución directa a la comunidad.

\section{Bibliografía}

Alfonso Alemán, A.L. (2008). Modelo de gestión de la responsabilidad social cooperativa directa. Estudio de caso: cooperativa de producción agropecuaria Camilo Cienfuegos. Centro de Estudios de Desarrollo Cooperativo y Comunitario, Facultad de Ciencias Económicas, Universidad de Pinar del Río: Tesis presentada en opción al grado científico de Doctor en Ciencias Económicas.

Bulgarelu, W. (1967). Elaboração do Direito Cooperativo. São Paolo: Ed. Atlas S.A.

Coque, J. (2008). Puntos fuertes y débiles de las cooperativas desde un concepto amplio de gobierno empresarial. Madrid: REVESCO, págs.: 65-93.

Corbella, C. (1990). Régimen jurídico de las cooperativas. Buenos Aires: Intercoop, Ed. Cooperativa Ltda.

Cracogna, D. (1986). Estudios de Derecho Cooperativo, Buenos Aires: Intercoop, Ed. Cooperativa Ltda. 
- (1992). Problemas actuales del Derecho Cooperativo. Buenos Aires: Intercoop, Ed. Cooperativa Ltda.

FAURA, I., \& UDINA, T. (2004). La actividad de las cooperativas de consumidores. Economía Social: La actividad económica al servicio de las personas (vol. 6, págs. 146-159). Fundación Cajamar.

GarcíA Müllek, A. (2012). El acto cooperativo, construcción latinoamericana. Recuperado de www.aidcmess.com.ar/.../Alberto\%20Garcia\%20Mulle...

- (2015). Derecho Cooperativo y de la Economía Social y Solidaria. Mérida: Asociación Iberoamericana de Derecho Cooperativo, Mutual y de la Economía Social y Solidaria.

Kaplan de Drimer, A., \& Drimer, B. (1981). Las cooperativas. Fundamentos. Historia. Doctrina. Buenos Aires: Intercoop, Ed. Cooperativa Ltda.

Naranjo Mena, C. (2014). La naturaleza jurídica de la cooperativa y el acto cooperativo. SIBULE: Asesores Legales. Recuperado de http://www.sibule. com/\#! La-Naturaleza-Jur\% C3\% ADdica-de-la-Cooperativa-y-el-ActoCooperativo/c104m/1

Rezzónico, A. (2006). Reflexiones sobre el acto cooperativo. Revista Idelcoop, págs. 388-397.

RodRíGuez MUSA, O. (2013). La autonomía cooperativa y su expresión jurídica. Una aproximación crítica a su actual implementación legal en Cuba. Universidad de Deusto: Boletín de la Asociación Internacional de Derecho Cooperativo, No. 47, págs.: 129-155.

- (2017). La constitucionalización de la cooperativa. Una propuesta para su redimensionamiento en Cuba. Brasilia-DF: Coletânea IBECOOP No. 1, Ed. Vincere Asociados.

SANCHIS, J.R. \& ReVUelto, L. (1995). Análisis estratégico y crecimiento eterno de las cooperativas de consumo españolas. Facultad CC.EE. y EE. de la Universltat de Valencia, págs. 139-167.

ToRiBIOS, E. (2014). La Economía Social en España. Un análisis de las cooperativas de consumidores y usuarios. Palencia: Universidad de Valladolid.

Torres Morales, C (s/f). Reconocimiento del acto cooperativo en la legislación peruana. Recuperado de http://www.teleley.com/articulos/art_221013a.pdf Salinas Puente, A. (1954). Derecho Cooperativo. México: Ed. Cooperativismo.

Tristá Arbezú, G. (2015). Cooperativas no Agropecuarias. La Habana: Conferencia ofrecida y reproducida a militantes del Partido Comunista de Cuba por la Comisión de Implementación de los Lineamientos del Partido y la Revolución.

VICENT ChuLIÁ, F. (1991). Compendio crítico de Derecho Mercantil. Barcelona: Ed. José M. Bosch.

Zııocchi, G. (s/f.): Autogestión social de obras y servicios públicos locales. Lo «público no estatal» a partir de un estudio de caso en la ciudad de Córdoba. Recuperado de http://unpan1.un.org/intradoc/groups/public/ documents/clad/unpan000168.pdf 


\section{Otros documentos}

ACI (2004). Análisis del modelo cooperativo en el nuevo escenario económico. Primer taller ideológico. Panamá. Obtenido de http://www.aciamericas. coop/IMG/AnalisisdelModeloCooperativo.pdf

ACI-AmérICA (2009). Ley Marco para las Cooperativas de América Latina. Recuperado de http://www.aciamericas.coop/lMG/pdf/LeyMarcoAL.pdf

- (2016). Balance Social Cooperativo: certificación de Cooperativas de las Américas en Responsabilidad Social Cooperativa. Recuperado de www. aciamericas.coop.com

VI Congreso del Partido Comunista de Cuba (2011). Lineamientos de la Política Económica y Social del Partido y la Revolución. La Habana. Recuperado de www.cubadebate.cuwp-contentuploads201105folleto-lineamientos-vicong.pdf

VII Congreso del Partido Comunista de Cuba (2016). Actualización de los Lineamientos de la Política Económica y Social del Partido y la Revolución para el período 2016-2021. La Habana. Recuperado de http://www.cubadebate. cu/especiales/2016/09/13/vea-el-texto-integro-de-la-actualizacion-de-loslineamientos-para-el-periodo-2016-2021-pdf

- (2016). Conceptualización del Modelo Económico y Social Cubano de Desarrollo Socialista, La Habana. Recuperado de http://www.cubadebate. cu/wp-content/uploads/2016/05/Conceptualizacion-Modelo-EconomicoSocial-Cubano-Desarrollo-Socialista.pdf

- (2016). Plan nacional de desarrollo económico y social hasta 2030: Propuesta de visión de la nación, ejes y sectores estratégicos. La Habana. Recuperado de http://www.cubadebate.cu/noticias/2016/04/17/informe-centralal-vii-congreso-del-partido-comunista-cuba

\section{Legislación}

Ley 113, Del Sistema Tributario, en Gaceta Oficial de la República de Cuba, Edición Ordinaria N. ${ }^{\circ}$ 053, La Habana, 21 de noviembre de 2012.

Decreto-Ley 305 «De las Cooperativas no Agropecuarias», en Gaceta Oficial, Edición Extraordinaria No. 053, La Habana, 11 de diciembre de 2012.

Decreto-Ley 306 «Del Régimen Especial de Seguridad Social de los Socios de las Cooperativas No Agropecuarias», en Gaceta Oficial, Edición Extraordinaria No. 053, La Habana, 11 de diciembre de 2012.

Decreto No. 309 «Reglamento de las Cooperativas no Agropecuarias», en Gaceta Oficial, Edición Extraordinaria No. 053, La Habana, 11 de diciembre de 2012. 